\title{
Post-Secondary Aspirations of High School Seniors from Different Social-Demographic Contexts
}

\author{
G. PATRICK O’NEILL*
}

\begin{abstract}
This study examines post-secondary aspirations of high school seniors from five different residential settings (rural farm, rural nonfarm, village, small-town, and large city) in the Regional Municipality of Durham (Durham Region), Ontario, Canada. A linear regression model sorts out simultaneous effects of the independent variable, residential locale, on the dependent variables, levels of educational and occupational aspiration, with relevant control factors held constant. Results indicate that differences between groups is minimal as residential locale accounts for only a small proportion of the variance in aspirational levels. Nevertheless, as a group, rural nonfarm students have the highest overall levels of post-secondary aspiration, small-town and city students have moderate levels of postsecondary aspiration, and rural farm and village students have the lowest overall levels of post-secondary aspiration. Two variables, in particular, account for most of the variance in the model, namely, parental expectations and peer group. In general, the findings contribute to a better understanding of factors which affect divergent levels of postsecondary aspiration among high school seniors in Durham Region and in areas which approximate Durham Region.
\end{abstract}

\section{RESUME}

Cette étude examine les aspirations post-secondaires des élèves de dernière année de cinq cadres résidentiels différents (rural ferme, rural non-ferme, le village, la petite ville et la grande ville) de la municipalité régionale de Durham, (la Région de Durham), Ontario, Canada. Un Modèle de régression linéaire classe les effets simultanés de la variable indépendante, l'endroit résidentiel sur les variables dépendantes, les niveaux d'aspirations pédagogiques et professionnelles, en gardant invariables des facteurs pertinents de contrôle. Les résultats indiquent que les différences entre les groupes sont minimes puisque les endroits résidentiels n'expliquent qu'une petite proportion de la divergence des niveaux d'aspirations. Néanmoins, comme groupe, les élèves rurals non-fermes possèdent, dans l'ensemble, les niveaux d'aspiration post-secondaires les plus élevés, les élèves de petites villes et de grandes villes possèdent les niveaux d'aspiration post-secondaires modérés et les élèves du

* College of Education, Brock University. 
village et rurals fermes possèdent, dans l'ensemble, les niveaux d'aspirations post-secondaires les moins élevés. Deux variables, en particulier, expliquent le plus la divergence du modèle, à savoir, les espérances des parents et les pairs. En général, les conclusions aident à mieux comprendre les facteurs qui influent sur des niveaux divergents d'aspirations post-secondaires parmi les élèves de dernière année de la région de Durham et les régions qui s'en rapprochent.

\section{INTRODUCTION}

Numerous studies have appeared, in the past twenty years, that have attempted to account for differential levels of educational and occupational aspiration among high school students. To date, most research efforts have focused on individual and family background attributes. Of all the factors studied, gender, socioeconomic status and mental ability (intelligence) have been found to be most consistently and clearly associated with levels of aspiration. ${ }^{1}$ In addition, the social context in which individuals reside has occasionally caught the attention of researchers and practioners of social and educational theory. The term social context refers to either direct or indirect influences, or both, that an environment has on an individual's attitudes, beliefs, expectations, and aspirations.

This investigation focuses on one particular contextual variable, namely community of residence (residential locale). An attempt is made to examine effects of residential context on levels of educational and occupational post-secondary aspiration among high school seniors from five distinct social-demographic settings: rural farm (RF), rural nonfarm (RNF), village (VIL), small-town (SMT), and large city (LC). More precisely, the concern of this inquiry is with a contextual explanation of variability in the postsecondary aspirations of Canadian high school seniors in the Regional Municipality of Durham (Durham Region), Ontario, Canada. This explanation is presented by constructing and testing a linear regression model which incorporates influences due to certain personal, psychological, social-psychological variables, and the social-demographic variable, residential locale.

\section{LITERARY REVIEW}

A critical review of the literature indicated that, while American aspirational studies have been profuse, there is need for more comparative and contemporary Canadian research (Fleming, 1957:4; 1965:8-9; Pike, 1970:10). Evidence obtained from previous ruralurban surveys (Burchinal, 1961; Christiansen, 1962; Grigg and Middleton, 1960; Sewell, 1964; Sewell and Orenstein, 1965; Siemens and Driedger, 1965; Youmans, 1956), as well as other related works (Anisef, 1973; Breton, 1972; Fleming, 1957; Porter, Porter, and Blishen, 1973; Sperry et al., 1965) suggests that rural youth, especially males, have, on the average, lower levels of post-secondary aspiration than their small-town or large city counterparts. Further, small-town adolescents have generally had lower levels of aspiration than high school seniors from large urban centers. In other words, the larger the community of residence (as measured by population count), the higher the overall level of student post-secondary aspiration. As a rule, this trend has held regardless of sample size, particular cutting points employed for determining high and low aspirations and criteria used for classifying communities. 


\section{LITERARY CRITIQUE}

The research cited, while convincing, poses four extremely complex problems of interpretation resulting from insufficient control of potentially confounding variables, confusion in definition and measurement of the concept aspiration, general failure to consider rural-urban school differences, and failure to directly estimate the magnitude of residential effects. First, contaminative effects caused by spurious associations can only be eliminated when all factors known to be differentially related to the dependent variable (aspirational levels) while, at the same time, suspected to be unevenly distributed within categories of the independent variable (residential locale), are equalized or matched within all categories of the independent variable. Negligence, in this respect, on the part of past research raises a grave question. That is, could so-called differences in aspirational levels be artifacts resulting from failure to simultaneously control the influence of factors known, or believed, to be differentially associated with both residential locale and levels of aspiration? Indeed, other types of aspiration and vocation oriented studies have established separate and significant relationships between the variables mental ability, family socioeconomic status, sex, parental expectations, and school peer group, on the one hand, and levels of aspiration on the other hand (O'Neill, 1978). In addition, research has established separate and significant relationships between the variables family size and levels of aspiration (Anisef, 1973; Breton, 1972; Elder, 1965; Rehberg and Westby, 1967; Porter, et al., 1973; Wilson and Buck, 1960) and family position and levels of aspiration (Altus, 1966; Breton, 1962; Rosen, 1961; Rossi, 1965; Sampson, 1962). Yet, as stated, earlier studies did not sort out contaminative effects due possibly to these seven confounding factors. Therefore, it is not known whether their joint effects would greatly reduce, or for that matter, completely eliminate reported relationships between residential locale and levels of aspiration. Hence, these seven factors along with one additional factor entitled "citification" were built into the present model.

The variable, "citification", was included as a control factor because rural populations are widely variant in their compositions. Some live adjacent to large urban centres, while others live in more remote areas. It was suspected that ruralites living on the periphery of large urban communities might have greater exposure to urban life-styles and ideals than those residing in isolated regions. In fact, Firey, Loomis, and Beegle (1967) have shown that data on birth rates, on delinquency, on subscription to large daily newspapers, and so on, form more or less concentric tiers around a central city. Each tier reveals successively less urban acculturation as one moves outward from the central core of the city. Now, if the original premise drawn from the literature review, is correct, then proximity to a central city could affect levels of rural aspiration due possibly to varying degrees of urban acculturation. Thus, the need to control for possible disparity in urban exposure in a study such as this.

Secondly, relatively little explicit attention has been given to a clear conceptualization of the terms "aspiration" and "expectation". In fact, there has been much misunderstanding in interpreting students' post-secondary plans because of the inter-changeable and synonymous use of the terms aspiration and expectation (Rodman, Voydanoff, and Lovejoy, 1974: 184-85). Moreover, some researchers fail to realize that different dimensions are involved in the notion aspiration. For instance, aspiration is sometimes defined as the role that an individual wants or would like to have (idealistic choice). At other times, it is defined as the role that the individual accepts or is resigned to attaining (realistic choice) (Haller and Miller, 1971: 8,56). These two dimensions clearly 
differ from each other. Young people often distinguish between what they would like to accomplish and what they are really sure they can accomplish. Yet, the term aspiration has frequently been used for either dimension and different terms have been used for the same dimension (Kuvlesky and Bealer, 1966: 265-69). Thus, in aspirational studies, one must distinguish not only between the concepts aspiration and expectation, but also between "real" and "ideal" choices, or researchers could be reporting different aspects of supposedly the same concept. This study eliminates the problem by making clear distinctions between the terms aspiration and expectation, on the one hand, and between realistic and idealistic preferences on the other hand.

Thirdly, inter-regional differences in educational resources (human and physical) were continually neglected as rural and urban samples were drawn from different administrative units. If there were resource disparities in the school systems, and there is strong evidence to suggest that this was a distinct possibility (Edington, 1970: 73, 78; Hilton, 1949: 10-14; Humphreys, 1970: 43-45; Youmans, 1963: 5-6), the units themselves may have deprived rural students of equal access to certain educational materials, library volumes, counselling aids, special teaching personnel, and so on. Resource deprivation may have, in turn, restricted rural students' overall levels of post-secondary aspiration. The problem is arrested somewhat in this investigation as all subjects were drawn from the same administrative unit thereby controlling for the distribution and utilization of resources within schools. Moreover, this approach gives a degree of uniformity to such variables as student-teacher ratio, methods of instruction, evaluation and promotion as well as to the operational goals underlying school curriculums.

Finally, there remains the question of how to estimate the magnitude of residential effects, a problem not tackled directly in the works cited. As a rule, designs stopped with crosstabular analysis giving percentage distributions of the independent variable within categories of the dependent variable. The estimation, as distinct from detection and distribution, of such effects appears to be a generic problem for which explicit explanatory rural-urban aspirational models have not yet been proposed. This inquiry proposes one such model.

\section{THE MODEL AND ITS VARIABLES}

As stated, the purpose of this study is to generate and test a linear regression model which examines post-secondary aspirations of high school seniors from five social-demographic settings. The model includes eight control variables, one independent variable, and two dependent variables. The operational definition of each variable is presented along with a brief description of how it was measured. The eight control factors are: mental ability (intelligence), family socioeconomic status, sex, school peer group, parental expectations, family size, family position and citification.

Mental Ability. The variable intelligence was based on scores derived from the Culture Fair Intelligence Test (Cattell and Cattell, 1960a, 1960b). High, medium, and low mental ability ratings were obtained by dividing all raw scores into near equal thirds.

Family Socioeconomic Status. Students were divided into low, middle, and upper socioeconomic status levels according to their fathers' occupational rating(s) on Blishen's Revised Socioeconomic Index for Occupations in Canada 
(Blishen, 1976). Three proportionate socioeconomic groups were arrived at by combining seventy, sixty, and fifty ratings into high socioeconomic status (upper class), forty ratings into medium socioeconomic status (middle class), and thirty, twenty, and ten ratings into low socioeconomic status (working class).

Sex. For computer purposes, males were given a one rating and females were given a two rating.

School Peer Group. The variable was dichotomized into positive and negative socializing effects. Students who indicated that "most to all" of their friends were planning on a post-secondary education were considered to have a positive peer group impetus. Contrariwise, students with "few to no" post-secondary oriented friends were classified as having a negative peer group impetus.

Parental Expectations. In this text, expectations and aspirations are not congruent terms. Expectation connotes prediction, desire, and hopeful anticipation for others. Tersely stated, A has expectations for B, but B has aspirations for himself (Haller, 1968: 484-85). Subjects were asked to respond to questions which recorded their perceptions of their parents' attitude toward their future plans. The variable was trichotomized in to low, medium, and high encouragement categories. The low category signifies no or little post-secondary expectation, the middle category includes diploma granting colleges and the high category indicates degree granting universities.

Family Size. This variable refers to the number of siblings in the family. Small families included one or two children; medium, three or four children; and large, five or more children.

Family Position. Family position indicates the rank of the child within the family unit: oldest, intermediate or youngest.

Citification. Rural respondents (RF, RNF, VIL) were asked to check the number of times they visited a large urban centre. The variable was dichotomized into those who frequently visited a large urban centre (one or more times a week) and those who rarely visited a large city (once or twice a month or less).

The contextual independent variable, residential locale, is based upon the size and location of a student's place of residence. The variable was conceptualized and measured as a set of five separate entities: rural farm, rural nonfarm, village, small-town and large city. All students living on farms (agriculturally productive or hobby), regardless of where they attended high school, were classified as farm residents. However, adjustments in socioeconomic status had to be implemented because the Blishen Socioeconomic Index for Occupations in Canada (Blishen, 1976: 75) ranks all farmers as common labourers. Yet, in Durham Region, there is great variation within the group as a whole. For instance, many farm residents can be classified as part of both the farm and nonfarm labour force. Hence, a more precise socioeconomic assessment was obtained by reassigning farm students on the Blishen scale according to the following three criteria:

1. Farm residents who received their total income from farm production.

2. Farm residents who had two separate sources of income, farm and nonfarm.

3. Farm residents who received no income from the farm, worked outside the farm, and used the farm for residence only.

The first group were assigned working class status on the scale as farmers generally rate low on education (grade school or some high school) and prestige, two of the key determinants of status on the scale. The twos were given a combined rating based on their 
fathers' farm and nonfarm vocation. The average of the two was used to assign individual student ratings. The threes were given ratings based entirely on their fathers' nonfarm occupation(s).

Students living in the open country, but not on farms, were considered to be rural nonfarm residents. Subjects living in small country hamlets of less than 1,000 population were categorized as village inhabitants. Students living in places of 1,000 to 10,000 population were labelled small-town residents, and individuals residing in places with 50,000 to 150,000 population count were classified as city dwellers. ${ }^{2}$ In order to improve response accuracy, a list of cities, towns and villages, in Durham Region, was built into the questionnaire.

The two dependent variables in the study are educational and occupational aspirations. The former variable refers to students' post-secondary educational plans while the latter variable refers to students' vocational or occupational ambitions after school.

The concept, level of aspiration (Haller and Miller, 1971: 7-8; Haller, Otto, Meier, Ohlendorf, 1974: 114), includes an orientation towards a goal. The person's goal is a selection of one among the alternative behaviour levels that are possible with respect to an objective. The alternative behaviour levels must vary in the degree to which they are difficult to achieve. That is, the alternatives must be ranked in a continuum of difficulty. The person's choice is fluctuant in that its central tendency may lie at any point or limited range of points along the continuum of difficulty. The central tendency of the person's orientation is the point or limited range of points which has the highest valence for that individual. This is the person's level of aspiration. ${ }^{3}$ The term differential level of aspiration logically implies variation in the point of valence when it is estimated at different times on the same person, or at same or different times on different persons. In this study, the term is restricted to variations among different persons at the same time.

The concept, level of occupational aspiration, (LOA) is a special instance of the more general term. It differs from the general concept only in that it takes as its object the occupational hierarchy, and the continuum of difficulty consists of the various levels along the hierarchy. Level of occupational aspiration was measured by Haller and Miller's (1971) Occupational Aspiration Scale (OAS). The range of possible scores on the OAS is from zero to seventy-two. Low, medium and high levels of occupational aspiration were obtained by dividing all raw scores into approximate thirds.

The concept, level of educational aspiration, (LEA) is likewise a special case of the more general concept. It differs from the general concept only in that it takes as its object the post-secondary educational hierarchy, and the continuum of difficulty comprises the various levels along the hierarchy. The hierarchy contained nine alternatives: trade school with an apprenticeship in the field, agricultural college, business school or college, institute of technology, military college, the Ontario College of Art, theological seminary, community college, and university.

A threefold classification system developed in which the definitely decideds and the partially decideds were given precedence over the undecideds. A university choice definitely or partially decided was given a high rating. An undecided university choice was given a medium rating. Selection of a diploma granting college was also given a medium rating if the student indicated either a definite or partial decision to attend. Low ratings were given to college undecideds, to those who had no post-secondary aspirations, and to those who planned to pursue a trade with an apprenticeship in the field. 


\section{HYPOTHESIS AND COROLLARIES}

The model tests the premise that among high school seniors there is a significant relationship between social-demographic contexts and levels of post-secondary aspiration when relevant control factors are held constant. In general terms, the inquiry asks:

1. Does community of residence (residential locale) have a significant influence on students' post-secondary aspirations?

2. Does the zero-order association persist when relevant control factors are separately, successively or simultaneously controlled?

3. How much variance does residential locale account for over and above that accounted for by the control variables?

In response to these questions, the alternative hypothesis assumes the affirmative. That is, residential locale will have a significant influence on students' post-secondary aspirations over and above that of the control factors. Accordingly then, the main rank-order alternative hypothesis becomes:

The greater the degree of residential urbanization (as measured by population count), the higher will be the overall level of student post-secondary aspiration.

Breakdown by residential category leads to four specific corollaries.

Corollary 1.0

Students from large cities will have, on the average, higher levels of postsecondary educational and occupational aspirations than any one of the smalltown, village, rural nonfarm, or rural farm groups.

Corollary 2.0

Small-town students will have, on the average, higher levels of post-secondary educational and occupational aspirations than any one of the village, rural nonfarm or rural farm groups.

Corollary 3.0

Village students will have, on the average, higher levels of post-secondary educational and occupational aspirations than either their rural nonfarm or rural farm counterparts.

Corollary 4.0

Rural nonfarm students will have, on the average, higher levels of postsecondary educational and occupational aspirations than rural farm students.

\section{PROCEDURES}

The study was conducted in high schools under the jurisdiction of the Durham Board of Education in the Regional Municipality of Durham (Durham Region), Ontario, Canada. The region is divided into two geographic and economic zones - a highly industrialized, urbanized, southern corridor and a northern rural farming area. There are no ethnic enclaves in the region, although there has been a small influx of new immigrants in the last ten years. Low rental housing is minimal as are elite dormitories. The small-towns to the north and the larger cities to the south serve as drawing areas for shopping, recreation and business activities.

The region and surrounding areas offer all citizens ample opportunities for postsecondary education. Within easy driving distance are three universities and three com- 
munity colleges. Trent University is located to the east at Peterborough, while Scarborough College, University of Toronto, is located to the immediate southwest. Durham Community College is located within the Oshawa-Whitby corridor, while to the east again at Peterborough is situated Sir Sanford Fleming College with a branch campus at Lindsay. To the north, at Orillia, is Georgian Community College and the Wilfrid Laurier University extension program.

The sample consisted of four stratified grade twelve clusters ( 750 students) within each of two small-town and two large city high schools. Three instruments, the Occupational Aspiration Scale (OAS), the Culture Fair Intelligence Test, and the Survey Schedule, were administered to subjects in the late fall and early winter of the $1975-76$ school year. Of particular note is the fact that the Survey Schedule included three questions aimed at helping control for possible cultural deprivation and migratory effects among foreign born and migrant students in both rural and urban communities. Data were gathered on place of birth, length of attendance in present high school and length of stay in present household. When incorporated into the analyses, this information permitted a further computerized refinement of the sample as the computer could be programmed to select students according to the following three criteria: (1) only Canadian born students, (2) only students who had attended the same high school since grade nine, and (3) only students who had resided in their present household for over five years.

Two types of analyses, using the Statistical Package for the Social Sciences (SPSS) (Nie, Hull, Jenkins, Steinbrenner and Bent, 1975), were performed on the data. First, a series of crosstabulations established zero-order relationships and linearity between each of the control factors and each of the two dependent variables respectively - a prerequisite in the use of linear regression. Secondly, a series of regression equations, in the form of one-way analysis of variance with option nine (SPSS, ANOVA), was employed to measure rough and refined effects of residential locale on both educational and occupational aspirations. In option nine, all effects including main effects, covariate effects, ${ }^{4}$ and any interaction effects are assessed simutaneously as in straight multiple regression (SPSS, REGRESSION). Each effect is the additional contribution to the explained variation in the dependent variables after adjustment has been made for all other effects.

\section{RESULTS}

Table $1 \mathrm{~A}$ and $1 \mathrm{~B}$ present the rough effects of residential locale on each dependent variable. Only rough effects are measured because individual factors are not controlled for either separately, successively or simultaneously. According to Table 1A, residential locale has a statistically significant zero-order relationship with both educational aspiration $(p \leqslant .01)$ and with occupational aspiration $(\mathrm{p} \leqslant .05)$.

The significant effects of each residential category are shown in Table 1B. The unadjusted deviations are the means of each category expressed as deviations around the grand means of occupational and educational aspirations. As illustrated, residential locale accounts for approximately 1.3 per cent $(.013 \times 100=1.3)$ of the variance in occupational aspiration and approximately 2.2 per cent $(.022 \times 100=2.2)$ of the variance in educational aspiration. Table 1B also presents the rank-orders of the five residential groups. From highest to lowest, it is small-town (0.14), rural nonfarm (0.06), city (0.01), rural farm $(-0.07)$, and village $(-0.27)$ respectively for educational aspiration. Although city students rank first on occupational aspiration (0.08), small-town and rural nonfarm 


\begin{tabular}{lcccc}
\hline Occupational Aspiration & Sum of Squares & D/F & F Value & P \\
\hline Residential effects & 5.528 & 4 & 2.47 & $.042^{*}$ \\
Residual & 478.434 & 725 & & \\
Total & 484.962 & 729 & \\
\end{tabular}

Educational Aspiration

\begin{tabular}{lrrrr}
\hline Residential effects & 9.963 & 4 & 4.05 & .003 \\
Residual & 446.725 & 725 & & \\
Total & 456.088 & &
\end{tabular}

750 cases were processed.

20 cases ( 2.7 per cent) were missing.

\footnotetext{
* The statistical significance of the relationships examined throughout the analysis is determined by appropriate tests using the .05 probability level $(p \leq .05)$.
}

students both rank second (0.04), rural farm students are third $(-0.07)$, and village students are fourth $(-0.23)$.

The second equation included the eight covariates, the independent variable, and the two dependent variables. Only three of the eight covariates (parental expectations, family socioeconomic status, and school peer group) had statistically significant relationships with both dependent variables. As a result, the variables, family size, family position and citification were dropped from the equation. The logic behind this decision lies in the optimum choice of A and $B_{i}$ coefficients. When the best linear "fit" has been obtained, the inclusion of additional variables add little, if anything, to the explained variation in the dependent variables and can thus be discarded. Although sex and mental ability likewise had nonsignificant associations with both dependent variables, they were retained on an exploratory basis because the literature abounds with confirmed relationships between sex and aspirations, on the one hand, and mental ability and aspirations on the other hand.

The third and fourth equations include the five covariates, the independent variable, residential locale, and the dependent variables, occupational and educational aspirations, 


\section{TABLE $1 B$}

THE UNADJUSTED DEVIATIONS OF THE FIVE

RESIDENTIAL CATEGORIES AROUND THE GRAND

MEANS OF OCCUPATIONAL AND EDUCATIONAL ASPIRATION

\begin{tabular}{|c|c|c|}
\hline \multirow{2}{*}{ Residential Locale } & \multicolumn{2}{|c|}{ Unadjusted Deviations for: } \\
\hline & Occupational Aspiration & Educational Aspiration \\
\hline 1. Rural farm & $-0.07(3)^{\star}$ & $-0.07(4)$ \\
\hline 2. Rural nonfarm & $0.04(2)$ & $0.06(2)$ \\
\hline 3. Village & $-0.23(4)$ & $-0.27(5)$ \\
\hline 4. Smal1-town & $0.04(2)$ & $0.74(1)$ \\
\hline 5. Large city & $0.08(1)$ & $0.01(3)$ \\
\hline \multirow{3}{*}{$\begin{array}{l}\text { Summary } \\
\text { Measures }\end{array}$} & Grand mean $=2.00$ & Grand mean $=2.18$ \\
\hline & Multiple $R^{2}=.013$ & Multiple $R^{2}=.022$ \\
\hline & Multiple $R=.116$ & Multiple $R=.148$ \\
\hline
\end{tabular}

* In this and all successive tables, numbers in parentheses give the hierarchical order of each residential category.

respectively. In both cases, the computer was programmed to select the refined sample (only Canadian born students, only students who had attended the same high school since grade nine, and only students who had resided in their present house-hold for over five years). According to Table $2 \mathrm{~A}$, only parental expectations, family socioeconomic status, and school peer group have statistically significant relationships with occupational aspiration.

The nonsignificant effects of each residential category are shown in Table 2B. The unadjusted and adjusted deviations are the means of each category expressed as deviations around the grand mean of occupational aspiration. Without adjustments, city students rank first, small-town second, rural nonfarm third, rural farm fourth, and village fifth. With adjustments, there is considerable change in order; the covariates having their greatest effects on the village category. Rural nonfarm students rank first, city second, smalltown third, rural farm fourth, and village fifth.

Eta squared $(\eta)^{2}$ represents the proportion of variance in the dependent variable explained by the unique contribution of residential locale plus the common attributes of residential local and the five covariates. In contrast, Beta squared $(\beta)^{2}$ is the exclusive contribution of residential locale devoid of covariate overlap. Accordingly, residential locale makes a 2.6 per cent $(.026 \times 100=2.6)$ joint contribution to the variance in occupational aspiration. However, when adjustments are made for the five covariates, its unique contribution drops to less than one per cent $(.008 \times 100=0.8)$. The multiple 
$\mathrm{R}$ squared value of 0.281 ( 28 percent) represents the total amount of variance accounted for in the dependent variable by the additive effects (common and unique) of each covariate and the independent variable. The multiple $R$ value of 0.51 gives the strength of the multiple relationship between the dependent variable and the independent variable plus the five covariates. In this case, it is a moderately strong positive relationship.

Results for educational aspiration by residential locale are shown in Tables 3A and 3B. According to Table $3 \mathrm{~A}$, three of the five covariates (parental expectations, school peer group and sex) and the independent variable, residential locale, have statistically significant associations with the dependent variable, educational aspiration. The significant effects of each residential category are illustrated in Table 3B. With adjustments, rural nonfarm students rank first, small-town second, city third, village fourth, and rural farm fifth. In addition, residential locale makes a 2.6 per cent joint contribution to the variance in educational aspiration. However, its unique contribution drops to 1.4 per cent when adjustments are made for the five covariates. In total, the model accounts for approximately 41 per cent of the variance (multiple $\left.\mathrm{R}^{2}=.406\right)$ in educational aspirations. This, in turn, is reflected in the multiple $R$ of 0.63 which suggests a strong positive multiple relationship between the dependent variable and the independent variable plus the five covariates.

\section{DISCUSSION}

The results of this study are in partial agreement with past works in the field. Theory and empirical investigation claimed an hierarchical order in adolescents' overall levels of educational and occupational aspirations. Supposedly, that order was dependent, to some extent, upon degree of urbanization as measured by population count. In other words, there was a positive correlation projected between levels of aspiration and size of community of residence such that the greater the population density, the higher the overall level of student post-secondary aspiration. Presumably, then, city students, as a group, should rank first, small-town students second, village third, rural nonfarm fourth, and rural farm fifth in terms of aspirational levels. Yet, this order was not consistently maintained in the present inquiry. Rural nonfarm students, as a group, continually had higher levels of post-secondary educational and occupational aspirations than any one of the large city, small-town, village or rural farm groups. City students ranked second on occupational aspiration and third on educational aspiration. Small-town students, on the other hand, ranked second on educational aspiration and third on occupational aspiration. Village and rural farm students remained low on the continuum alternating between fourth and fifth position.

In terms of the main rank-order hypothesis, then, only one of the original four corollaries can be accepted, albeit conditionally. Caution must be exercised because residential locale does not have a statistically significant relationship with occupational aspiration. This means, in essence, that no acceptable degree of confidence can be attached to results for occupational aspiration. Nevertheless, the variable is retained throughout the discussions because it was stated in the first instance and ipso facto merits comment, and secondly independent rank-orders were similar for both educational and occupational aspirations. Corollary 4.0 then is conditionatly confirmed. That is,

Rural nonfarm students do have, on the average, higher levels of post-secondary educational and occupational aspirations than rural farm students. 
A ONE-WAY ANALYSIS OF VARIANCE WITH OPTION 9 , OCCUPATIONAL ASPIRATION BY RESIDENTIAL LOCALE CONTROLLING SIMULTANEOUSLY FOR THE FIVE COVARIATES

\begin{tabular}{lcccc}
\hline Independent Variables & Sum of Squares & D/F & F Value & $p$ \\
\hline Covariates & 80.024 & 5 & 32.674 & .001 \\
Parental expectations & 22.309 & 1 & 45.543 & .001 \\
$\begin{array}{l}\text { Family socioeconomic } \\
\text { status }\end{array}$ & 8.733 & 1 & 17.829 & .001 \\
Intel ligence & 0.125 & 1 & 0.256 & $.999 \star$ \\
School peer group & 11.939 & 1 & 24.373 & .001 \\
Sex & 0.518 & 1 & 1.058 & .305 \\
\hline Residential locale & 2.506 & 4 & 1.279 & .276 \\
\hline Residual & 224.835 & 459 & & \\
Total & 312.988 & 468 & & \\
\hline
\end{tabular}

511 cases were processed.

42 cases (8.2 per cent) were missing.

* If the F value is not greater than 1, SPSS does not compute the $p$ value. Instead, it prints .999.

Similarly, corollaries 1.0 and 2.0 are partly and conditionally confirmed. In short,

Students from large cities and small-towns (urban residents) have, on the average, higher levels of post-secondary educational and occupational aspirations than either their village or rural farm counterparts (rural residents).

\section{INTERPRETATION}

Before proceeding with an interpretative a posteriori explanation of the rank-orders, a word of warning is necessary. Observations are made that attempt to treat various factors in terms of casual linkages. The author, however, is quite aware of the fact that, technically speaking, cause and effect deductions can never be proven, only inferred. In short, one does not see a cause. Nevertheless, as a rule, inferred cause and effect arguments require both structural and temporal sequence. The following interpretations attempt such sequentiality.

Why then do rural farm and village students rank low and rural nonfarm students high in terms of post-secondary aspirations? What factors contribute to these phenomena? 
TABLE 2B

THE UNADJUSTED AND ADJUSTED DEVIATIONS

OF THE FIVE RESIDENTIAL CATEGORIES AROUND

THE GRAND MEAN OF OCCUPATIONAL ASPIRATION

Residential Locale $\begin{aligned} & \text { Unadjusted } \\ & \text { Deviations }\end{aligned} \quad \begin{gathered}\text { Adjusted for } \\ \text { Covariate Deviations }\end{gathered}$

1. Rural farm

$-0.06(4)$

$-0.05(4)$

2. Rural nonfarm

0.01 (3)

0.08 (1)

3. Village

$-0.34(5)$

$-0.14(5)$

4. Sma11-town

0.06 (2)

$-0.04(3)$

5. Large city

$0.11(1)$

$0.07(2)$

$\begin{array}{ll} & \text { Grand Mean }=2.00 \\ & \text { Multiple } R^{2}=.281 \\ \text { Summary } & \text { Multiple } R=.514 \\ \text { Measures } & \text { Eta }{ }^{2}=(0.16)^{2}=.026 \\ & \text { Beta }^{2}=(0.09)^{2}=.008\end{array}$

Can they be isolated and identified? Although somewhat sparse, the literature nevertheless provides some clues. For instance, evidence indicates that farm children cherish values consonant with country living. Willits and Bealer (1963) found that many farm youth strongly identify with rural values and believe that urban life is not superior to farm life (ethnocentrism). Moreover, these values are probably reinforced through membership in farm associations which are often outside the realm of other adolescents (peer group effects). ${ }^{5}$ Yet, as Pike (1970) notes, rustic values and beliefs often preclude access to higher education,

One cannot entirely ignore the argument pursued by some sociologists that a concomitant of the rural and small town environments is a set of values, beliefs, and ways of doing things - i.e., a subculture - which adversely affects access to higher education. According to this argument, the rural life - and particularly the life of the farmer - tends to be oriented to the concrete and the practical, and actively discourages the creation of the theoretical and abstract case of mind which is (or is supposed to be) inseparable from involvement in high education.

Thus, early and continuous indoctrination into traditional rustic values, coupled with parental support (parental expectation), may be the crucial factors in dissuading many farm youth from pursuing a post-secondary education. 
TABLE $3 A$

A ONE-WAY ANALYSIS OF VARIANCE WITH OPTION 9 ,

EDUCATIONAL ASPIRATION BY RESIDENTIAL LOCALE

CONTROLL ING SIMULTANEOUSLY FOR THE FIVE COVARIATES

\begin{tabular}{lcccc}
\hline Independent Variables & Sum of Squares & D/F & F value & $p$ \\
\hline $\begin{array}{l}\text { Covariates } \\
\text { Parental expectations }\end{array}$ & 113.975 & 5 & 60.681 & .001 \\
$\begin{array}{l}\text { Family socioeconomic } \\
\text { status }\end{array}$ & 0.362 & 1 & 0.964 & .999 \\
$\begin{array}{l}\text { Intelligence } \\
\text { School peer group }\end{array}$ & 0.352 & 1 & 0.937 & .999 \\
Sex & 6.358 & 1 & 16.925 & .001 \\
\hline $\begin{array}{l}\text { Residential locale } \\
\text { Residual }\end{array}$ & 1.664 & 1 & 4.428 & .034 \\
Total & 4.414 & 4 & 2.938 & .020 \\
\hline
\end{tabular}

511 cases were processed.

42 cases ( 8.2 per cent) were missing.

Perhaps a similar explanation can be applied to students from small villages. As a group, they may identify more strongly with rustic folkways and mores than their rural nonfarm counterparts. Indeed, many village residents are direct descendants of older local farm families. As such, they have numerous and close ties with farm friends and relatives. In fact, many village residents are recently retired or semiretired farmers who work in the local community as farm labourers. Subsequently, many young people may willingly accept seasonal employment, in the form of unskilled or semi-skilled work, in order to remain in the vicinity. Thus, village types are portrayed as part of the local establishment. They are permanent, traditional and arcadian. In short, they are countrified. ${ }^{6}$

In contrast, rural nonfarm families are seen as predominantly cosmopolitan in outlook. They are, strictly speaking, newcomers to the area. They have travelled extensively, lived in different communities and are more worldly oriented. They are transient, mobile and universal. Hence, they do not, nor cannot, identify with parochial attitudes and values. They foresee their destiny in the larger society, not in the immediate community.

Moreover, their attitudes and values are probably reinforced through constant contact with the larger society. Indeed, many parents of the rural nonfarm group work in the highly industrialized corridor to the south. Each day they trek back and forth from the 
TABLE 3B

THE UNADJUSTED AND ADJUSTED DEVIATIONS

OF THE FIVE RESIDENTIAL CATEGORIES AROUND

THE GRAND MEAN OF EDUCATIONAL ASPIRATION

\begin{tabular}{lcc}
\hline Residential locale & $\begin{array}{c}\text { Unadjusted } \\
\text { Deviations }\end{array}$ & $\begin{array}{c}\text { Adjusted for } \\
\text { Covariate Deviations }\end{array}$ \\
\hline 1. Rural farm & $-0.09(4)$ & $-0.11(5)$ \\
2. Rural nonfarm & $0.08(2)$ & $0.17(1)$ \\
3. Village & $-0.30(5)$ & $-0.09(4)$ \\
4. Small-town & $0.14(1)$ & $0.06(2)$ \\
5. Large city & $0.03(3)$ & $-0.03(3)$
\end{tabular}

$\begin{array}{ll} & \text { Grand Mean }=2.16 \\ & \text { Multiple } R^{2}=.406 \\ \text { Summary } & \text { Multiple } R=.634 \\ \text { Measures } & \text { Eta }^{2}=(0.16)^{2}=.026 \\ & \text { Beta }^{2}=(0.12)^{2}=.014\end{array}$

farm areas in the north to the southern metropolis. As commuters, they are constantly exposed to urban society. As a result, they are continually socialized by their colleagues and friends, adopt urban values, customs and ideas, and in tum, shape their children's aspirations along lines similar to those of city dwellers (parental expectations). Thus, many rural nonfarm students are doubly advantaged. They live in a rural environment, but identify closely with an urban setting. This affords them the advantages of both worlds - rural and urban. Yet, as stated, many rural farm and village parents are provincial in expectation. Their knowledge and influence is often restricted to the local community. Consequently, they can only provide limited indirect assistance in the larger society.

While the above interpretations have attempted to explain the hierarchical order among rural categories, care must be exercised because spread between groups was minimal. Remember, the magnitude of residential locale, in terms of unique variance accounted for in the dependent variables, ranged from a low of 0.8 per cent to a high of 1.4 per cent. Substantively speaking, these findings could be interpreted to mean that, in this study, residential locale can be dismissed as a factor related to aspirations of adolescents. Yet, residential locale, on the average, contributed more to the variance, in each dependent variable, than any one of sex, mental ability, family size, or family position - four variables frequently cited in the literature on studies related to aspirations. Hence it is tendered that even the small amount of variance accounted for by residential locale 
makes a contribution to the understanding of post-secondary aspirations among rural and urban youth in Durham Region.

The remainder of this discussion will attempt to account for residential locale's small contribution to the variance in the dependent variables and briefly comment on the linear regression model as a whole. Perhaps large significant differences between residential groups were not found because forces of urbanization have proceeded much further into rural Durham than was originally suspected. Better transportation and communication nexuses between rural and urban communities may have eliminated much presupposed rustic isolationism and conservatism.

A second explanation could be credited to migratory trends. The urban respondents (SMT, LC) studied may still be largely rural in their attitudes and values. That is, a large segment of the urban population may have come recently enough from rural areas so as to retain many of their rustic traditions and ideals. The reverse pattern could also be true. That is, many rural dwellers (RF, RNF, VIL) may be recent migrants from the city to the countryside. As a result, there may have been a general homogenization of rural and urban subcultures to the point where differences are now practically obscure. If this interpretation is correct, then Durham Region, as a geographic units, may be neither rural nor urban per se, but rather "rurban".?

Still, this investigation did control, to some extent, for cultural and migratory effects. Recall that the sample was refined to include: (1) only Canadian born students, (2) only students who lived in their present household for over five years, and (3) only students who had attended the same high school since grade nine. Yet, as inferred earlier, strong identification with a local community probably goes beyond a five year period. Future rural-urban aspirational studies should take this factor into account when developing comparative models.

Thirdly, some of the observed results may be peculiar to Durham Region. Perhaps greater differences would be found in samples drawn from regions including larger cities and more isolated hinterlands. Hence, it would be most unsound to generalize these findings freely to other regions or areas where social-demographic contexts greatly differ.

Finally, despite the small contribution of residential locale, overall, the linear regression model does have good explanatory powers. Indeed, the range of total variance accounted for, on the average, is quite substantial. This definitely indicates, therefore, that many major personal, psychological and social psychological variables are included in the model. Future studies should likewise take this factor into consideration when developing comparative models.

\section{FOOTNOTES}

1. For extensive bibliographic references to this literature, see Pavalko, R.M. and Bishop, D.R. Peer Influences on the College Plans of Canadian High School Students. Canadian Review of Sociology and Anthropology, 1966, 3, 191-200.

2. Statistics Canada, Census Division, 1971 Census of Canada (1973) defines places with over 1,000 population count as urban and places with less than 1,000 population count as rural. Counts below 1,000 are subdivided into rural nonfarm and farm households.

3. In other words, the point or points of greatest convergence (highest valence) on the continuum of difficulty is the subject's level of aspiration.

4. Control variables are referred to as covariates in the SPSS analysis of variance program.

5. Examples include 4-H Clubs, Future Farmers of America and Junior Grange. 
6. Possibly this same proposition is applicable to many small-town residents. However, its effects on overall ranking is probably less because of proportionate numbers.

7. Horton and Hunt $(1972: 443)$ define the term rurban as, "mixed areas which are neither urban nor rural".

\section{REFERENCES}

Altus, W.D. Birth order and its sequalae. Science, 1966, 151, 44-49.

Anisef, P. The critical juncture: Education and vocational intentions of grade 12 students in Ontario: Preliminary survey. Toronto: Ministry of colleges and universities, 1973.

Blishen, B.R. A revised socioeconomic index for occupations in Canada. The Canadian review of sociology and anthropology, February 1976, 13, 71-79.

Breton, R. Social and academic factors in the career decisions of the Canadian youth. Ottawa: Information Canada, 1972.

Buchinal, L.G. Differences in educational and occupational aspirations of farm, small-town and city boys. Rural sociology, 1961, 26, 107-121.

Cattell, R.B. and Cattell, A.K.S., Handbook for the culture fair intelligence test. Chạmpaigne, Illinois: institute for Personality and Ability Testing, 1960a.

Cattell, R.B. and Cattell, A.K.S., Manual for the culture fair intelligence test. Champaigne, Illinois: institute for Personality and Ability Testing, 1960b.

Christiansen, J.R. Educational and occupational aspirations of high school seniors in three central Utah counties. Salt Lake City: Brigham Young University, 1962.

Edington, E.D. Disadvantaged rural youth. Review of educational research 1970, 40, 69-85.

Elder, G.H. Family structure and educational attainment: A cross-national analysis. American sociological review, 1965, 30, 81-96.

Firey, W.; Loomis, C.P. and Beegle, J.A. The fusion of urban and rural. Pp. 214-222 in Paul K. Hatt and Albert J. Reiss, Jr. (Eds.), Cities and society. New York: The Free Press, 1967.

Fleming, W.G. Ontario grade 13 students: Who are they and what happens to them?. Atkinson study of utilization of student resources, report II. Toronto: Ontario College of Education, University of Toronto, 1957.

Characteristics and achievement of students in Ontario universities. Atkinson Study of utilization of student resources, report II. Toronto: Ontario College of Education, University of Toronto, 1965.

Grigg, C.M. and Middleton, R. Community of orientation and occupational aspirations of ninth grade students. Social forces, 1960, 38, 303-308.

Haller, A.O. On the concept of aspiration. Rural sociology, 1968, 33, 484-487.

Haller, A.O. and Miller, I.W. The occupational aspiration scale. Cambridge, Massachusetts: Schenkman Publishing Company, Inc. 1971.

Haller, A.O.; Otto, L.B.; Meier, R.F. and Ohlendorf, G.W. Levels of occupational aspirations: An empirical analysis. American sociological review, 1974, 39, 113-121.

Hilton, E. Rural school management. New York: American Book Company, 1949.

Horton, P.B. and Hunt, C.L. Sociology. Toronto: McGraw Hill Book Co., 1972.

Humphreys, E.H. Urban-rural disparity in Ontario elementary education. Toronto: The Ontario Institute for Studies in Education, 1970.

Kuvlesky, W.P. and Bealer, R.C. A clarification of the concept 'occupational choice'. Rural sociology, $1966,31,265-276$.

Nie, N.H.; Hull, C.H.; Jenkins, J.; Steinbrenner, K. and Bent, D.H. Statistical package for the social sciences. Toronto: McGraw-Hill Book Company, 1975.

O'Neill, G.P. Post-secondary aspirations of high school seniors in different school contexts: A Canadian study. The Alberta journal of educational research, 1978, 14, 137-155.

Pavalko, R.M. and Bishop, D.R. Peer influences on the college plans of Canadian high school students. Canadian review of sociology and anthropology, 1966,3, 191-200. 
Pike, R. Who doesn't get to university and why? Association of Universities and Colleges of Canada. Ottawa: The Runge Press Ltd., 1970.

Porter, M.R.; Porter, J. and Blishen, B.R. Does money matter? Prospects for higher education. Toronto: Institute for Behavioural Research, York University, 1973.

Rehberg, R.A. and Westby, D.L. Parental encouragement, occupation, education, and family size: Artifactual or independent determinants of adolescent educational expectation? Social forces, $1967,45,362-374$.

Rodman, H.; Voydanoff, P. and Lovejoy, A.E. The range of aspirations: A new approach. Social problems, 1974, 22, 184-198.

Rosen, B.C. Family Structure and achievement motivation. American sociolological review, 1961, 26, 574-585.

Rossi, A.S. Naming children in middle-class families. American sociological review, 1965, 30, 499-513.

Sampson, E.E. Birth order, need achievement, and conformity. Journal of abnormal and social psychology, 1962, 64, 155-159.

Sewell, W.H. Community of residence and college plans. American sociological review, 1964,29, 24-38.

Sewell, W.H. and Orenstein, A.M. Community of residence and occupational choice. American journal of sociology, 1965, 70, 551-563.

Siemens, L.B. and Driedger, L. Some rural-urban differences between Manitoba high school students. Winnipeg: Faculty of Agriculture and Home Economics, University of Manitoba, No. 4, 1965.

Sperry, I.V. and Others. Educational and vocational goals of rural youth in the south. Raleigh, North Carolina: North Carolina University, Southern coop bulletin 107. ERIC: ED 012 743, 1965.

Statistics Canada, Census Division, 1971 Census of Canada. Population, urban and rural distributions. Ottawa: Queen's Printer, February, 1973.

Willits, F.K. and Bealler, R.C. The utility of residence for differentiating social conservatism in rural youth. Rural sociology, 1963, 28, 70-80.

Wilson, P.B. and Buck, R. The educational ladder. Rural sociology, 1960, 25, 404-413.

Youmans, E.G. Occupational expectations of twelfth grade Michigan boys. Journal of experimental education, 1956, 24, 259-271.

The rural school dropout. Bulletin of the bureau of school service, volume 36 . Lexington: College of Education, University of Kentucky, 1963. 